\title{
Challenges in Learning English Prepositions by Kuwaiti EFL Learners: A Call for Bridging the Gap in Kuwait's New English Language Curriculum
}

\author{
Abdullah M. Alotaibi \\ Language Center, College of Business Studies, \\ Public Authority For Applied Education and Training, Kuwait \\ Shu-hua Wu \\ Language Center, College of Business Studies, \\ Public Authority For Applied Education and Training, Kuwait \\ Sulaiman Alrabah \\ Language Center, College of Business Studies, \\ Public Authority For Applied Education and Training, Kuwait
}

\begin{abstract}
This paper investigates the extent to which 80 students of bachelor and diploma's degree studying in PAAET are aware of the appropriate use of simple and complex prepositions in English. It is one paper within a series of papers that shed light on the areas of difficulties and challenges currently facing EFL learners in Kuwait who have graduated from government schools and have studied the English language curriculum implemented until 2016. In addition, it represents a base line to which the competence of Kuwaiti EFL learners can be measured and compared to the outcomes of the new curriculum which was implemented in 2016 (graduates of the new curriculum should be joining PAAET three years from now). In this paper, two groups of participants divided based on proficiency levels were given a multiple-choice test which was used to check their comprehension skills in choosing the right preposition in English. Error analysis revealed that $53.75 \%$ of students have difficulty in learning English prepositions and these difficulties co-relate to low levels of English proficiency. The research shows that Kuwaiti EFL learners have little awareness of English prepositions due to a number of reasons including $L 1$ negative transfer and the intralingual errors. The researchers hope that the implementation of the new English curriculum should encompass linguistics, cognitive and effective goals in teaching and learning English prepositions if it takes into consideration the common errors Kuwaiti EFL learners perform.
\end{abstract}

Key words. Prepositions, New Kuwait national curriculum, language transfer and intralingual, error analysis and acquisition.

\section{INTRODUCTION}

The present paper investigates the shortcomings found in Kuwait's current English language curriculum which lasted until 2016 by examining the performance of Kuwaiti students who graduated from government schools in one aspect of English language which is the use of prepositions. The accurate use of prepositions is one segment of the grammar that EFL students in Kuwait should learn and master throughout their progression in study in Kuwaiti public school. Furthermore, it is attested that EFL students usually face difficulties in learning the appropriate use of English prepositions (Sudhakaran, 2015; Delija, 2013; Yousefi, 2014). Any curriculum change should take into consideration how to overcome this well-known difficulty amongst EFL learners. Therefore, this paper aims to achieve several goals: first, it 
presents an example of the current level of competence among EFL learners in their use of English prepositions through analyzing the errors they make in a specially designed test presented in this research. Second, it sheds light on the areas of difficulties facing these students in learning English prepositions. Third, it should act as a base or reference used for comparison - in the near future - between the level of competence in Kuwaiti EFLs who undertook the old curriculum and those who have undertaken the new one in order to show whether new curriculum was able to overcome these difficulties. Although the third goal is not attainable in the current paper, this paper will, never the less, present some recommendations for current teachers of EFL students and for policy makers involved in the new curriculum.

The paper is organized as follows. Section 2 starts with a background and literature review covering four main aspects: a) The importance of prepositions in Second language acquisition; b) the effectiveness of error analysis in studying EFL learners' performances; c) pedagogical methods used to teach prepositions; d) the situation in Kuwait. The fourth aspect, section 2.4 includes a number of subsections covering some background on the following: a) the common errors by Kuwaiti EFL learners in general; b) the description of the properties and standards adopted in Kuwait's new educational curriculum in general; c) the standards specific to the English language curriculum. This background is followed by the main research questions in section 3. Section 4 covers the research methodology; section 5 covers the results and discussion; and section 6 ends the paper with the conclusion and recommendations.

\section{LITERATURE REVIEW}

\section{Prepositions and Their Importance in Second Language Acquisition}

Several dictionaries propose different definitions of the term preposition in the relevant literature. For example, in Cambridge dictionary, a preposition in grammar is a word that is used before a noun, a noun phrase, or a pronoun connecting it to another word. In Meriam Webster dictionary, prepositions are defined as showing direction, location, or time or to introduce an object. They are usually followed by a noun, noun phrase, or pronoun.

Furthermore, it has been observed that prepositions are considerably used in daily life conversations. However, mastering the use of prepositions is viewed as an area of difficulty for EFL learners in General (Lorincs, 2012; Yousef et al, 2014; Delija, 2013) and for Arab learners in particular (Tahaineh, 2010; Al-Quda, 2013). In fact, they are considered one of the most problematic areas for teachers and for learners of English (Lindstromberg, 1991; Lorincs, 2012). There are many reasons why prepositions are found to be difficult for English learners, some of these reasons relate to the properties of prepositions in English and to the difference between the properties of prepositions when compared to the learners L1. Lornicz and Gorden (2012) indicate that there are several factors why English prepositions are found to be difficult for learners of English. First, English prepositions are "polysemous" which means that a lot of them can have a variety of meanings depending on context. For example, a preposition such as in indicates location either in time or space and can be used to indicate containment. The exact meaning of a preposition would be affected by the semantics of its complement noun and therefore the preposition's meaning is rather functional and not straightforwardly lexical. This factor causes frustrations amongst learners when trying to determine the prepositions meaning and use it appropriately (Koffi, 2010 cited in Lorincz and Gorden, 2012). Second, several English prepositions are monosyllabic hence difficult to recognize, particularly in oral speech, such as on, for and to (Lam, 2009). As a result, language learners may not be able to recognize prepositions in rapid, naturally occurring speech. Third, the sheer number of prepositions in the English language also contributes to their difficulty. English has up to 120 prepositions. Therefore, it seems difficult for language learners to systemize English prepositions (Lorincz and Gorden, 2012:1). When comparing English to Arabic prepositions for 
example, it is noted that some English prepositions are morphologically complex formed from two or more words such as apart from - which is categorized as compound prepositions - or by means of - which is known as phrasal prepositions. Arabic prepositions on the other hand are most commonly simple prepositions made from one word only such as fii 'in', ilaa 'to' etc. (Almarrani.2009). All these factors can contribute to the difficulty seen in the acquisition of English prepositions.

Furthermore, it has been shown that the most frequent prepositions in English such as in, for, with, within and about cause the most errors ascribed to negative transfer from L1 (Blom, 2006). Negative transfer from L1 is the use of a learner's first language in a second language context resulting in a non-target like second language form. Sometimes, the result of the transfer from the learner's first language to the second language is a correct form in the target language hence it is labelled positive transfer (Gass \& Selinker, 2001). Other types of errors are described as interlingual and intralingual errors. Interlingual errors are errors ascribed to transfer from the mother tounge (Almahammed, 2016:45) while intralingual errors are developmental errors resulting from difficulties in the acquisition of the target language (Almahammed, 2016:50). Many current studies indicate that errors committed in L2 can be attributed to both language transfer and developmental factors or intralingual interference (Bilal et al,2013; Tahaineh, 2010).

In this paper, both simple and complex prepositions are chosen to test the participants performances. The choice of both simple and complex prepositions, despite that Arabic lacks complex prepositions, is to allow for a clearer identification of instance of negative and positive transfer from Arabic during error analysis. More precisely, English language prepositions can be grouped as complex prepositions which do not exist or have equivalent in Arabic or oneword prepositions (simple prepositions) that might have an equivalent in Arabic. It is important to mention that many prepositions in English language cannot be treated as prepositions in Arabic (Almahammed, 2016:38).

\section{Error Analysis}

Research on second language acquisition has witnessed various studies to account for the process of L2 acquisition in many languages around the world. Among these processes is the Error Analysis (EA) which became an important part of applied linguistic analysis, since it focuses not only on errors committed by learners but also on the language being learned (Abi samara, 2003). The outcome of (EA) was viewed by Magnan (1983:383) as follow: “...we now view language learning as a series of stages of interlanguages, and errors as positive evidence that learners are experimenting with linguistic rules in order to progress from one interlanguage stage to the next". EA has played a major role in research on L2 acquisition (Gorokhova, 1990).

In addition, EA was used to shed light on the possible reasons of grammatical errors and elicit accurate conclusions and justifications. Suthakaran (2015), reports that the most commonly used method for the assessment of competence in the use of prepositions is Error Analysis (EA). Many researches revealed that prepositional errors of substitution, omission and addition accounts for the majority of syntactic errors amongst EFL (Tahainneh, 2010; Almahammed, 2016; Alhysony, 2012; Delije \& koruti, 2013; Yousefi, 2014). Errors of commission are defined as when an action was not warranted, actively doing something wrong. Errors of omission are defined as not acting when action was warranted or failing to actively do something right (Wagner\&Weitzman,2015). These errors can be related to either the pressure of the patterns of the mother tongue on L2 on the one hand, or to the imperfect learning of new L2 patterns on the other hand. This suggests that some of these errors are related to the teaching aspect of the process, i.e. teachers failing to teach the new L2 patterns 
accurately. It is hence recommended that teachers become aware of the most common errors made by students in learning a specific grammatical aspect of English. Teachers in general are not aware of these errors and Kuwait teachers are no exception. This knowledge would therefore allow for a more effective pedagogical method in teaching prepositions. In other words, "in order to determine what pedagogical methods are most effective, it is important to first understand what makes learning prepositions so difficult", as argued convincingly by Lorincz and Gorden (2012:1).

\section{Pedagogical Methods in Teaching Prepositions}

In their study, Lorincz and Gorden (2012) discuss three different common pedagogical methods which are currently in use to teach prepositions comparing their advantages and disadvantages. The first method is the traditional approach; teaching prepositions through explicit grammar instruction. The focus of this approach by students is on learning prepositions individually within context, with no further expansion (Lam, 2009:3). Lam's (2009) study revealed that students who were taught using this traditional method had little confidence in their ability to properly use prepositions and had minimal retention rates.

The second method is the collocation approach. In this approach students can be taught using "chunks" or words that often occur together. Researchers believe that such forms may be stored as chunk initially, but after repeated exposure they are more closely analyzed by the learner. Furthermore, teaching prepositions through collocations allows for analyzing language by studying structures and lexical patterns found in digital data bases (Koosha and Jafarpour, 2006). The criticism for the use of collocations is that it avoids any unifying insight about the relations between particular words which leads to uneconomical use of the learner's time in and out of class. (Lindstromberg, 1996).

The Prototype Approach is the third method discussed. This Approach is based on lakoff's prototype theory which claims that prepositions have multiple meanings, but one meaning thought to be the most dominant or prototypical. However, Lorincz and Gordon (2012:4) argue that while researches may not agree on a particular strategy for teaching prepositions, it is clear that the traditional manner of teaching them individually is not sufficient. Both the collocationist approach and the prototypical require that learners be exposed to a plethora of input. (p.4).

In Kuwait, the Ministry of Education in 2016 has adopted a new English curriculum follows an up-to-date competence and standard-based approach which is learner-centered and adaptive to the changing needs of students, teachers and society (Teachers guidebook, 2016:29). The previous curriculum followed the traditional approach which many researchers claim that it is insufficient for teaching prepositions. This claim is supported in this paper which examines Kuwaiti EFL learners' level of competence in their use of prepositions through analyzing the errors. The details of the results are discussed in section 5. In this paper, the researchers argue that in order for any change in the pedagogical approach to be effective it should study the common errors learners commit in each aspect of the grammar. This is the purpose of the series of studies conducted by Alotaibi (2014, 2016a-c), Alotaibi \& Alajmi (2015) and Alotaibi \& Alotaibi (2015a-c, 2017a-b). In the mean while the following section describes the current situation in Kuwait and presents the main high lights of the new curriculum.

\section{The Situation in Kuwait: Kuwaiti EFL Learners and Kuwait's English curricula. Common Grammatical Errors by Kuwaiti EFL learners}

Research on Kuwaiti EFL learners show that both beginners who are just starting to grasp the basics of English grammar and also the advanced students who can speak quite fluently, both 
make grammar mistakes. These mistakes include choosing the wrong tense, omitting articles, misusing adverbs and adjectives, wrong word order, using the wrong prepositions and incorrect comparative. In numerous studies, Alotaibi (2014, 2016a-c), Alotaibi \& Alajmi (2015) and Alotaibi \& Alotaibi (2015a-c, 2017a-b) identify the most common grammatical mistakes Kuwaiti student make and try to analyze them in perspective of the short coming of Kuwaiti national curriculum in place and the teaching methods applied.

More specifically, Alotaibi (2014) conducted a study regarding the comprehension of English lexical collocations by Kuwaiti EFL Learners. The findings indicated that the most frequent types of errors among learners were [adjective + noun] and [verb (action) + noun/ pronoun/ prepositional phrase]. It was also added that these errors were due to the Li interference and the lack of knowledge of lexical collocations among learners.

Another study by Alotaibi \& Alajmi (2015) was conducted regarding the acquisition of the passive alternation by Kuwaiti EFL learners. The errors found were difficulties with verbs that do not passivize, the overgeneralizing of the passivization rule, and the confusing of noncausative with the passive construction.

Alotaibi \& Alotaibi (2105a) conducted a study regarding the comprehension and production of English grammatical collocations by Kuwaiti EFL learners. The findings indicated that the most frequent type of grammatical errors was on the ones which have prepositions, especially those which have misleading equivalent in Arabic.

Another study by Alotaibi \& Alotaibi (2015b) regarding the acquisition of binomials by Kuwaiti EFL learners showed that Kuwaiti EFL learners had little awareness of binomials. That was attributed to several reasons such as, L1 negative interference, the existence of culture specific items and the lack of exposure to these items.

Alotaibi \& Alotaibi (2105c) examine the syntactic proficiency of Kuwait EFL learners with tag questions as an example. The findings indicated that Kuwaiti EFL learners are not aware of the syntax of tag questions due to the non-existence of tag questions in Arabic.

In addition, Alotaibi (2016a) conducted a study to see whether the participants have the ability to distinguish between verbs which show locative alternation between the figure-object-frame and the object-ground-frame and verbs that do not, which is known as a learning paradox. The results show that some participants performed better on the locative alternating verbs over the non-alternating ones. Furthermore, the study showed that there is positive transfer from L1 which affected the students answers a lot.

Alotaibi (2016b) conducted a study to examine the learnability of English relative clauses. The findings indicated that the English proficiency level affected their answers of the test. The errors made were deletion of the relative pronoun, wrong relative pronoun, repetitive use of resumptive pronouns, passivization of the relative clause and problems with indirect object and negative relative clauses. These indicate that Kuwait EFL learners are unaware of many underlying syntactic operations in English due to their non-existence in Arabic.

Alotaibi (2016c) shows that the use of inflectional morphemes by Kuwaiti EFL learners indicate that $(64.5 \%)$ of learners had some awareness of the complex nature of the inflectional morphemes in English to a certain degree. Most of the errors are due to first language (L1) negative transfer and the irregularity of some types of inflectional morphemes. 
Another study by Alotaibi, M. \& Alotaibi, A. (2017a) focuses on the acquisition of the prenominal adjective orders by Kuwaiti EFL learners. The result shows that the types of errors made by the participants were due to first language (L1) negative transfer. Their second research in (2017b) investigates the acquisition of derivational suffixes by Kuwaiti EFL learners. The study examines their ability to comprehend and produce derivational suffixes in English. The overall percentage of the correct answers showed that Kuwaiti EFL learners may have some awareness of the complex nature of the derivational suffixes in English to certain degree. The errors made were due to first language (L1) interference and the modification that non-natural derivational suffixes cause when they are attached to the word (stems/roots).

All the above research shows that there are different reasons for the difficulties facing Kuwaiti EFL learners. One of the most important challenges is L1 interference and the pressure from the patterns of grammar from Arabic on the learners. In addition, it was made clear that the previous traditional pedagogical approach to English was insufficient both in teaching English language patterns and to account for L1 interference. Therefore, it is highly recommended that the new approach incorporates for L1 interference and the effect of the mother language grammar in addition to applying the new competence-based approach which is described in detail below.

\section{Rationale Behind Kuwait's New National Curriculum}

Looking at this new national curriculum in a more specific way, it is based on the competence children and students aged 6 to 18 are supposed to acquire and the learning achievement standards that indicate to what extent this process effectively happens over the school years and/ or at different stages of the process.

According to the new curriculum vision of the Ministry of education, the Kuwait national Curriculum adopts this modern and up-to dated competence and standards-based approach. That requires a shift from the old curricula that are content based and with a different rationale to foreign language teaching (An integrated approach to foreign language teaching).

A curriculum that emphasizes the complex outcomes of a learning process (i.e. knowledge, skills and attitudes to be applied by learners) rather than mainly focusing on what learners are expected to learn. In principle such a curriculum is learner-centered and adaptive to the changing needs of students, teachers and society. It implies that learning activities and environments are chosen so that learners can acquire and apply the knowledge, skills and attitudes to situations they encounter in everyday life.

Summarized in points, the main idea of competency-based curriculum illustrates:

1. Instead of objective, think 'competences',

2. Instead of content, Think 'outcomes',

3. Learners activities will be based on performance of learners and accomplishment of criteria (standards),

4. Teaching activities are learner-centered,

5. Formative evaluation is necessary.

\section{Curriculum and standards for English recommended for Kuwaiti EFL learners}

The English language curriculum aims to develop students' language awareness regarding English. The English language curriculum is organized as follow: English is taught from grade 1 to12 .Its overall scope is, on the one hand, to support students to understand oral and written texts (through listening and reading) and, on the other, to produce (oral and written texts by participating as individuals or members of a group in a variety of communicative activities, By 
the end of grade 12, students should achieve level B2 of the common European Framework of references for language (CEFR). The following table illustrates the levels of achievements Kuwait students are expected to attain at different stages according to the CEFR.

Table 1: CEFR for different stages

\begin{tabular}{|l|l|l|}
\hline Stages of education & Grades & CEFR levels \\
\hline Primary & $1-2$ & A1 \\
& $3-5$ & A2 \\
\hline Intermediate & $6-9$ & B1 \\
\hline Secondary & $10-12$ & B1 \\
\hline
\end{tabular}

Based on the balanced presence in the subject curricula of elements of language taught in a functional way and elements of culture, by the end of secondary learning students will develop competences to: (1) Use English in a correct, fluent, creative and personal way; (2) Express ideas and feelings, engaged in productive dialogue; and (3) use English effectively in oral and written form of communication. Furthermore, Singer et al (2013) named the eight key competences of the Kuwait curriculum among them is the competence of the English language which is demonstrated as follows:

Table 2: The structure of general competence for English language (Singer et al, 2014:478)

\begin{tabular}{|l|l|l|l|}
\hline $\begin{array}{l}\text { English } \\
\text { Language }\end{array}$ & $\begin{array}{l}\text { Doing } \\
\text { what? }\end{array}$ & With what? How? & In which context? \\
\hline & Listening to & $\begin{array}{l}\text { Oral messages by means of } \\
\text { different strategies }\end{array}$ & $\begin{array}{l}\text { In a variety of contexts for } \\
\text { effective comprehension }\end{array}$ \\
\hline & Speaking & $\begin{array}{l}\text { By using strategies of individual } \\
\text { and interactive speech. }\end{array}$ & $\begin{array}{l}\text { In a variety of communicative } \\
\text { contexts }\end{array}$ \\
\hline & $\begin{array}{l}\text { Reading } \\
\text { and viewing }\end{array}$ & $\begin{array}{l}\text { A range of texts by means of } \\
\text { different strategies }\end{array}$ & $\begin{array}{l}\text { In a variety of communicative } \\
\text { contexts }\end{array}$ \\
\hline & Writing & A range of texts & $\begin{array}{l}\text { Adapted to a variety of } \\
\text { communicative purposes }\end{array}$ \\
\hline
\end{tabular}

This is a structure of a key competence of the Kuwait curriculum in order to make students communicate effectively in English, in a range of contexts.

We hope that the new curriculum can account for instances of L1 interference in the case of Kuwaiti EFL learners. However, these hopes can only be confirmed after the researches conducted by Alotaibi el at - are duplicated in three years -time on a similar sample of learners. The proposed research should allow researchers to compare the effectiveness of the implemented change in the new curriculum as compared to the old curriculum. It is expected that the students' proficiency should be higher if the implementation was successful.

\section{RESEARCH QUESTIONS}

Based on review of the literature and previous studies done in this area, this study aims to shedding some light on the following research questions:

1. Are Kuwaiti EFL learners aware of one word and complex prepositions in English?

2. To what extent is the usage of prepositions affected by EFL Learners' mother tongue (L1)?

3. Are their comprehension abilities influenced by their English proficiency level? 


\section{The Sample}

\section{METHODOLOGY OF RESEARCH}

The sample consisted of eighty students at the Public Authority of Applied Education and training (PAAET). Forty students from the College of Basic Education (CBE) (Bachelor degree and forty students from the College of Business Studies (CBS) (Diploma Degree). Their mean age was 20 years old, they were all native speakers of Kuwaiti spoken Arabic (KSA) and they have learned English according to Kuwait old international curriculum policy (which is subject-based curricula). To insure the validity of the results, the researchers selected the participants randomly from the groups (the Bachelor degree students and the diploma degree students). Since the participants' English proficiency level is an independent variable, the researchers grouped the participants based on their scores on the English placement test (EPT). In particular, those who scored 40-59 on their EPT were considered pre-intermediate, whilst those who scored 60-80 were considered advanced. Therefore, the 80 participants were divided into two groups (1) forty intermediate learners (diploma students): and (2) forty advanced learners (Bachelor degree students). It has been indicated by Lewis (2000) that participants with low English proficiency would not usually pass a test on English prepositions prior to reaching that point where they have a clear sense of learning; therefore, participants with low English proficiency level were not included in this study. It should be noted that the participation in this study was voluntary; the researchers explained the procedure to the participants, and only those who agreed to be involved were included.

\section{Instruments}

In order to measure the participants' ability to comprehend and produce correct examples of simple preposition or complex prepositions a multiple-choice test was used as an elicitation instrument to measure participants' comprehension of certain structure. So, the researchers opted for the multiple-choice test to determine whether the participants are aware of prepositions in English. Nicol (2007:54) point out that a multiple-choice test is usually used to measure participants' comprehension of a certain structure.

Furthermore, the prepositions in the test were chosen based on their frequency in the English text books taught to students at Kuwaiti government public school. The researchers included 16 simple prepositions and 10 complex prepositions as shown in table 3. Each preposition was used in one sentence, hence the test included 26 questions altogether (See appendix A). Participants were asked to choose one correct answer from the multiple-choices.

Table 3: Simple and Complex prepositions used in the test

\begin{tabular}{|l|l|}
\hline Simple prepositions & complex prepositions \\
\hline off & away from \\
throughout & in favor of \\
over & $\begin{array}{l}\text { putside of } \\
\text { within }\end{array}$ \\
up & with regard to \\
since & on board \\
inside & as well as \\
until & close to \\
in & in view of \\
to & next to \\
with & \\
at & \\
for & \\
after & \\
on & \\
before & \\
\hline
\end{tabular}




\section{The statistical analysis}

For the purpose of this study, the Statistical Package for the Social Sciences (SPSS) was used to analyze the participants' answers on the test for this study, the researchers calculated the means of the participants' answers in both two groups (The Bachelor degree) and (the Diploma degree). The reason for using the means was to (1) determine whether there are any statistically significant differences between the two groups regarding their answers on the test; and (2) identify the most problematic type of prepositions i.e. simple vs. complex prepositions.

\section{RESULTS AND DISCUSSION}

The main goal of this study is to measure the comprehension of Kuwaiti EFL learners in terms of using simple and complex prepositions in English, and to account for the errors, if found. It also investigates whether the participants' English proficiency level affects their answers on the test. An examination of table 4 demonstrates that Bachelor degree students (54.2\%) performed better than diploma students (40.5\%) on the test. Additionally, table 4 shows that the total mean of all answers by both bachelor students and diploma students on both types of prepositions was (47.35) This result shows that all Kuwaiti EFL learners have little awareness of prepositions in English.

Table 4: Results of (Diploma) and (Bachelor) students for simple and complex preposition

\begin{tabular}{|llll|}
\hline & Bachelor & Diploma & Means of total answers \% \\
\hline Simple preposition & $57.05 \%$ & $45 \%$ & $51.25 \%$ \\
\hline Complex preposition & $50.9 \%$ & $36 \%$ & $43.45 \%$ \\
\hline Mean f total answer & $54.2 \%$ & $40.5 \%$ & $47.35 \%$ \\
\hline
\end{tabular}

Despite the small differences in the percentages between Diploma and Bachelor, there is statistically significant differences between the two groups in terms of understanding the English simple prepositions and the complex prepositions. The statistical significance (0.01) is lower than (0.05) as shown in table 5. This means that English proficiency level plays an important role in the comprehension of simple and complex prepositions by Kuwait EFL Learners.

Table 5: Results of t-test of differences between Diploma and bachelor students

\begin{tabular}{|c|c|c|c|c|c|c|}
\hline & $\mathrm{N}$ & $\mathrm{M}$ & SD & $\mathrm{T}$ & $\mathrm{df}$ & Sig \\
\hline \multicolumn{7}{|c|}{ Proficiency level (Simple prepositions) } \\
\hline Bachelor degree Students & 40 & 1.57 & 0.239 & -2.839 & 78 & 0.01 \\
\hline Diploma degree Students & 40 & 1.45 & 0.23 & -2.839 & 78 & 0.01 \\
\hline \multicolumn{7}{|c|}{ Proficiency level (Complex prepositions) } \\
\hline Bachelor degree Students & 40 & 1.50 & 0.260 & -2.260 & 78 & 0.01 \\
\hline Diploma degree Students & 40 & 1.37 & 0.165 & -2.260 & 78 & 0.01 \\
\hline
\end{tabular}

* Significance level $>0.05$

Tables 6 and 7 provide a clear and comprehensive description of the results, showing in detail the percentages of wrong answers on each item on the test i.e., simple and complex prepositions. For the readers' convenience, the researchers divided the results into two tables as follows; table 6 shows the participants' results on simple preposition, whereas table 7 shows the participants' results on complex preposition. 
Table 6: Percentage of Wrong answers for simple prepositions.

\begin{tabular}{|lccc|}
\hline Simple preposition & BA Learners & Diploma learners & Mean of total answers \\
\hline Off & $45 \%$ & $78 \%$ & $61.5 \%$ \\
Throughout & $53 \%$ & $78 \%$ & $65.5 \%$ \\
Over & $33 \%$ & $43 \%$ & $36.5 \%$ \\
within & $75 \%$ & $90 \%$ & $82.5 \%$ \\
Up & $48 \%$ & $65 \%$ & $56.5 \%$ \\
Since & $28 \%$ & $23 \%$ & $26.5 \%$ \\
Inside & $38 \%$ & $45 \%$ & $41.5 \%$ \\
In & $43 \%$ & $50 \%$ & $41.5 \%$ \\
Before & $35 \%$ & $30 \%$ & $32.5 \%$ \\
With & $23 \%$ & $33 \%$ & $26.5 \%$ \\
At & $38 \%$ & $50 \%$ & $44 \%$ \\
On & $50 \%$ & $68 \%$ & $59 \%$ \\
Until & $45 \%$ & $75 \%$ & $60 \%$ \\
For & $48 \%$ & $45 \%$ & $46.5 \%$ \\
After & $53 \%$ & $70 \%$ & $61.5 \%$ \\
To & $53 \%$ & $55 \%$ & $54 \%$ \\
\hline
\end{tabular}

Regarding the performance of both BA learners and Diploma learners in relation to the oneword simple prepositions it is clear that more than $50 \%$ of the simple prepositions are found to be problematic. The highest error rate was with the following prepositions: within (82\%), throughout (65\%), off and after (61.5\%). The researchers examined the wrong answers that students made in relation to questions A4, A2, A1 and A15. As for A4, 75\% of the BA learners got the answer wrong, whereas $90 \%$ of the Diploma learners got the answers wrong. When looking at the wrong answers made for this question, $60 \%$ of the students chose with instead of within, while $38 \%$ chose the answer d, which is no preposition. Question A4 is repeated here for convenience.

\begin{tabular}{|c|c|c|c|}
\hline Wrong answers for Question A4 & With & Except & No preposition \\
\hline $\begin{array}{l}\text { Approximate Percentage based } \\
\text { on wrong answers }\end{array}$ & $60 \%$ & $2 \%$ & $38 \%$ \\
\hline
\end{tabular}

It could be argued here that the similarity between with and within may have caused their wrong selections. However, this also indicates that many students are not aware of the difference between the prepositions with and within which suggests low knowledge of L2 patterns. A similar explanation could be given for the case of prepositions off in A1 as repeated below.

A1. I fell -------- the table and broke my hand.
a. of
b. off
c. like
d. -----

In the multiple questions the researchers chose to include both prepositions of and off to see whether students are aware of the different properties and uses of these seemingly similar prepositions. The results confirm that students were not fully aware of the difference between these two forms since $80 \%$ of the wrong answers chosen were for the preposition of instead of off.

\begin{tabular}{l|c|c|c} 
Wrong answers for Question A1 & Of & Like & No preposition \\
\hline $\begin{array}{l}\text { Approximate Percentage based } \\
\text { on wrong answers }\end{array}$ & $80 \%$ & $0 \%$ & $20 \%$
\end{tabular}


Both cases for within and off indicate low awareness of L2 patterns which is an intralingual factor. However, not all errors with prepositions can be argued to be related to intralingual factors but rather to interference from L1. This is the case, for example, with the preposition throughout in question $\mathrm{A} 2$ repeated below:
A2. It is raining the whole country.
a. via
b. on
c. throughout
d. -----

Out of the wrong answers chosen by students, $75 \%$ were for preposition on while $20 \%$ for via and the rest is for no preposition.

\begin{tabular}{l|c|c|c} 
Wrong answers for Question A2 & via & on & No preposition \\
\hline $\begin{array}{l}\text { Approximate Percentage based } \\
\text { on wrong answers }\end{array}$ & $20 \%$ & $75 \%$ & $5 \%$
\end{tabular}

It could be argued that this case is an example of L1 interference since in Arabic rain is usually collocated with the preposition 'alaa 'on', hence many participants chose preposition on. A similar example is question A15 with preposition after:

A15. My son Qutaiba is named ---------------- his grandfather.
a. afterb. to
c. over
d.--------

In this question more than $60 \%$ of the students got this answer wrong. When analyzing the errors made, it was clear that $50 \%$ of the wrong answers chose the prepositions over, while the rest were conflicted between either no preposition or the preposition to as indicated below.

\begin{tabular}{l|c|c|c} 
Wrong answers for Question A15 & to & over & No preposition \\
\hline $\begin{array}{l}\text { Approximate Percentage based } \\
\text { on wrong answers }\end{array}$ & $24 \%$ & $50 \%$ & $26 \%$
\end{tabular}

Again, it could be argued that this is an example of L1 interference since the expression of naming someone after someone else is expressed in Arabic as naming someone 'on' or 'over' someone else, where the preposition 'ala $a$ 'on' is usually used to collocate with the verb naming. This property of Arabic may have caused the learners to choose the preposition over instead of after, a case of negative interference. Nevertheless, the difficulty in this example may be related to the fact that the preposition after is not used to indicate actual position or direction but is used rather metaphorically to indicate succession. This is another layer of difficulty countered when interpreting the meanings of preposition that the learners may face; this difficulty is related to properties of English prepositions themselves.

On the other hand, there are prepositions that scored lower on the difficulty rates, i.e. less students got them wrong, which are with (26\%), since (26.5\%), before (32.5\%). This may be related to their frequent occurrence in the English books taught at high and intermediate schools and the similarity in meaning of these prepositions in Arabic.

Turning to complex prepositions, it is clear that 8 out of 10 prepositions were found difficult since more than $50 \%$ of the participants got the answers wrong as shown in the table below. 
Table 7: Percentage of wrong answers for complex prepositions

\begin{tabular}{|c|c|c|c|}
\hline Complex prepositions & BA Learners & Diploma learners & Mean of total answers $\%$ \\
\hline V+ away & $43 \%$ & $50 \%$ & $46.5 \%$ \\
\hline Outside of & $38 \%$ & $65 \%$ & $51.5 \%$ \\
\hline Prior to & $58 \%$ & $75 \%$ & $61.5 \%$ \\
\hline On board & $63 \%$ & $75 \%$ & $59 \%$ \\
\hline Close to & $45 \%$ & $58 \%$ & $51.5 \%$ \\
\hline Next to & $33 \%$ & $33 \%$ & $33 \%$ \\
\hline In favor of & $63 \%$ & $73 \%$ & $69 \%$ \\
\hline With regard to & $50 \%$ & $65 \%$ & $57.5 \%$ \\
\hline As well as & $45 \%$ & $63 \%$ & $54 \%$ \\
\hline In view of & $68 \%$ & $75 \%$ & $76.5 \%$ \\
\hline
\end{tabular}

The main argument here is that Arabic EFL learners in general face this difficulty with complex prepositions since complex prepositions are not common in their L1 grammar, i.e. Arabic. This indicates that learning patterns of L2 that do no have an equivalent in the learners L1 may in fact make learning these patterns difficult. Furthermore, teaching these prepositions by traditional methods appears to be unsuccessful considering the high percent of wrong answers amongst both low proficient and high proficient learners.

\section{CONCLUSION AND RECOMMENDATIONS}

This study shows that overall, Kuwaiti EFL learners in this study face some difficulties in their awareness of prepositions in English. Additionally, despite that proficiency level plays a central role in the comprehension of grammatical prepositions by Kuwaiti EFL, as seen in the difference between BA and Diploma learners, both groups experience difficulties with both simple and complex prepositions. It also shows that complex prepositions, as their name suggests, as also more difficult to learn than simple prepositions. There are many factors that cause these difficulties, the most noticeable are L1 interference causing negative interference in the case of simple prepositions. Another factor is the difficulty in acquiring new L2 patterns especially when these do not have a equivalent in the learners L1 as seen in the case of complex prepositions. Finally, this study with the series of studies done by the Kuwaiti researchers such as Alotaibi (2014, 2016a-c), Alotaibi \& Alajmi (2015) and Alotaibi \& Alotaibi (2015a-c, 2017a-b) indicate that Kuwaiti EFL learner face many challenges in learning English especially in relation to grammar. These results indicate that the previous curriculum which follows the traditional pedagogical approach is insufficient to foster for the learners needs and cannot accommodate for many factors hindering the learning of English such as L1 interference in addition to low proficiency levels in general. The researchers, however, hope that the new curriculum implemented in 2016 will account for many issues since it is learnercentered. The errors identified by the researchers of this series of papers should be taken into consideration to enhance the new English curriculum, since the first step in creating an effective pedagogical approach is to understand the places of difficulties facing the targeted learners.

\section{References:}

Abi Samara, N. (2003) 'An analysis of errors in Arabic speakers' English writing'. In Mourtage, K. (ed.) Investigating writing problems among Palestenian students studying English as a foreign language. Unpublished doctoral dissertation

Almahammad, Y. (2016) First language transfer in the acquisition of English prepositions by Jordanian EFL learners. Unpublished Ph.d Thesis.

AlMarrani, Y. (2009) 'A comparative and contrastive study of preposition in Arabic and English'. Language in India. 9, p 46-68

Alotaibi, A. (2014) 'The comprehension of English lexical collocations by Kuwaiti EFL learners'. International Journal Of English Language \& linguistic research. 2(3), p 1-12 
Alotaibi, A. M., Wu, S., \& Alrabah, S. (2018). Challenges in Learning English Prepositions by Kuwaiti EFL Learners: A Call for Bridging the Gap in Kuwait's New English Language Curriculum. Advances in Social Sciences Research Journal, 5(11) 516-530.

(2016a) 'The Acquisition of the English Locative Alternation by Kuwaiti EFL'. International Journal of Applied Linguistics 7 English Literature. 5(1), p 65-73

(2016b) 'Examining the learnability of English relative clauses: Evidence from Kuwaiti EFL learners'. English language teaching. 9(2), p 57-65

(2016c) 'The use of inflectional morphemes by Kuwaiti EFL Learners'. English language and literature studies. 6(3), p 32-41

Alotaibi, A. \& Alajmi, H.(2015a) 'The acquisition of the passive alternation by Kuwaiti EFL learners'. International Journal of English Linguistics. 5(1), p 44-52.

Alotaibi, A. \& Alotaibi, M. (2015a) 'The comprehension and production of English grammatical Collocations By Kuwait EFL learners'. International Journal of English language Teaching. 3(3), p 26-39

__ (2015b) The Acquisition of Binomials by Kuwaiti EFL Learners. International Journal of English Linguistics. 5(3), p 63-71. $\overline{8(8),}$ p $1-9$

(2015c) 'Syntactic proficiency of Kuwait EFL Learners: A study of tag Questions'. English language teaching.

Alotaibi, M. \& Alotaibi, A.(2017a) 'On the acquisition of the prenominal adjective order by Kuwaiti EFL learners'. Advances in language and literary studies. 8(1), p 1-8.

(2017b) 'On the acquisition of derivational suffixes by Kuwaiti EFL learners'. European Scientific Journal.13(17), p 223-238

Al-Qudah.H, (2013) 'Acquisition of some selected prepositions of time by English major undergraduate at Baqa University in Jordan'. English Language teaching .5(3), p 97-109

Bilal, H., Triq, A., Yaqub, A. and kanwal, S. (2013) 'Contrastive analysis of prepositional errors'. Academic research International, Vol.4, 5, p 562-570

Blom,L.(2006): Swedish Problems with English Prepositions. School of learning \& English communication. Jonk Oping University.p 41-60

Delija, S. and Koruti, O. (2013) 'Challenges in teaching Prepositions in a language classroom'. Journal of education and Practice.4(13),p 124-130

Ellis, R. (1997) Second language acquisition, Oxford: Oxford university press.

Gass, S. \&Selinker, L.(2001) Second language acquisition: An introductory course. $2^{\text {nd }}$ ed. U.S.A. Lawrence Erlbaum Associate. p 457.

Gorokhova, E. (1990) Acquisition of English articles by native speakers of Spanish. Rutgers . The State University of New Jersey, New Brunswick.

Jimenez, R.M. (1996) 'Frequency and variability in errors in the use of English prepositions'. Miscelanea: A Journal of English and American Studies. 17, p171-187.

Koffi, E. (2010) Applied English Syntax: Foundation for word phrase, and sentence analysis. Dubuque, Iowa: Kendall Hunt publishing company.

Koosha, M. \& Jafarpour, A.A. (2006) 'Data-driven learning and teaching collocation of prepositions: The case of Iranian EFL Adult Learners'. Asian EFL Journal, 8(4), p 192-209.

Lam, Y. (2009) 'Applying cognitive linguistics to teaching the Spanish prepositions por and para'. Language Awareness.18 (1), p 2-18.

Lindstomberg, S.(1996) 'Prepositions: Meaning and Methods'. ELT Journal. 50(3), p 225-236.

Lewis,M.(2000). 'Language in the lexical Approach'. In M. Lewis (ed), Teaching Collocation: Further Development in the Lexical Appraoch: Language teaching publications. p126-154.

Lorincz, K. and Gordon, R.(2012) 'Difficulties in learning Prepositions and Possible Solutions'. Linguistics Potfolio.1, 14.

Magnan, S.(1983) 'The applied linguistics cooperative: Today and Tomorrow'. The modern language Journal. 67(4), p 382-392

Muller, C.M. (2011) 'English Learners' knowledge of prepositions: Collocational Knowledge or knowledge based on meaning' System: an international Journal of Educational technology and applied Linguistics. 39 (4), p 480-490 
Suthakaran,B. (2015) 'Acquisition of English language prepositions in the absence of formal grammar teaching'. English Linguistics Research.4(4),p 88-99

Nicol,D.(2007). 'E-assessment by design: Using multiple-choice tests to good effect'. Journal of Further and Higher Education. 31(1), p 53-64

Singer, F. et al (2014) 'Developing a competence- based curriculum for the $21^{\text {st }}$ century: The case of Kuwait'. Procedia-Social and behavioral sciences.128, p 475-481

Tahaineh,Y.(2010):" A study of Arab EFL University students' errors in the use of prepositions”. MJAL. 2, p76-112.

Tryzna, M. \& Alsharoufi, H. (2017) 'English language education policy in Kuwait'. In: R.Kirpatrick (ed.) English language education policy in the Middle Eastand North Africa, Language policy13, D01 10.1007/978-3-31946778-8-6

Wagner, G. \& Weitzman, M.L. (2015) 'Errors of commission versus errors of omission in the globalist'. Columbia University Academic Commons Http://dx.doi.org/10.7916/D811V5DMW

\section{APPENDIX 1 \\ One-word prepositions (A)}

Choose the most suitable preposition (a, b, $c$ or d) for no preposition to fill in the blank

1. I fell -------- the table and broke my hand.
a. Of
b. off
c. like
d. -----

2. It is raining --------- the whole country.
a. Via
b. on
c. throughout
d. -----

3. It took me -------- an hour to do my homework.
a. On
b. over
c. up
d.-------

4. It is not ---------- my power to help you.
a. With
b. Within
c. except
d.-----

5. Ahmed and Ali ran --------- the hill.
a. Like
b. With
c. up
d.-------

6. Waleed has worked in a bank

2000.
a. Since
b. Alongside
c. beside
d.------

7. It was dark the room.
a. Than
b. Inside
c. beside
d.-------

8. I'll be ready to leave ---------about twenty minutes.
a. In
b. On
c. at
d.--------

9. It's only two weeks ------Christmas.
a. On
b. before
c. as
d. -------

10. Do you live ---------- your parents?
a. Than
b. With
c. to
d.--------

11. He has coffee $-7: 00$ am every morning.
a. On
b. in
c. at
d.------

12. I think Laila spent the entire afternoon the phone.
a. In
b. on
c. at
d.--------- 
13. I'll wait
a. Until
b. at
c. from

d.--------

14. my fingers were injured so my brother had to write those mails
a. To
b. with
c. for
d.-------me.

15. My son Qutaiba is named his grandfather.
a. After
b. to
c. over
d.--------

16. I have been married ------------- my wife for over 35 years.
a. Of
b. on
c. to
d.-------

\section{Complex- prepositions (B)}

Choose the most suitable preposition ( $a, b, c$ or $d)$ for no preposition to fill in the blank

1. The cat ran -------- the dog and escaped.
a. Away from
b. But for
c. because of
d.----------

2. Ali is not your idea . It won't work.
a. In spite of
b. Instead of
c. in favor of

d.----------

3. Take your hands your pockets and help me.
a. inside
b. outside of
c. up to

d.--------

4. I never spoke French ---------- living in France.
a. Thanks to
b. Prior to
c. up to
d.------

5. I'd like to talk to you your work.
a. With regard to
b. Up to
c. thanks to
d.------

6. Is there a doctor this plane?
a. On to
b. On board
c. on top of
d.------

7. You should telephone----------- write, just to be sure.
a. As to
b. as well as
c. but for
d.------

8. Your car is -------to my car. about two cars away.
a. Close to
b. contrary to
c. but for
d.------

9. --------of your illness, we will wait for a week.
a. In view of
b. instead of
c. in front of
d.-----

10. the school is-------the bank. between the hotel and the bank.
a. outside of
b. next to
c. in addition to
d.------ 